\title{
Scalable, high performance, enzymatic cathodes based on nanoimprint lithography
}

\author{
Dmitry Pankratov ${ }^{1,2}$, Richard Sundberg ${ }^{3}$, Javier Sotres ${ }^{1}$, Dmitry B. Suyatin ${ }^{3,4}$, \\ Ivan Maximov ${ }^{3}$, Sergey Shleev ${ }^{* 1,2,5}$ and Lars Montelius ${ }^{3,4}$
}

\section{Full Research Paper}

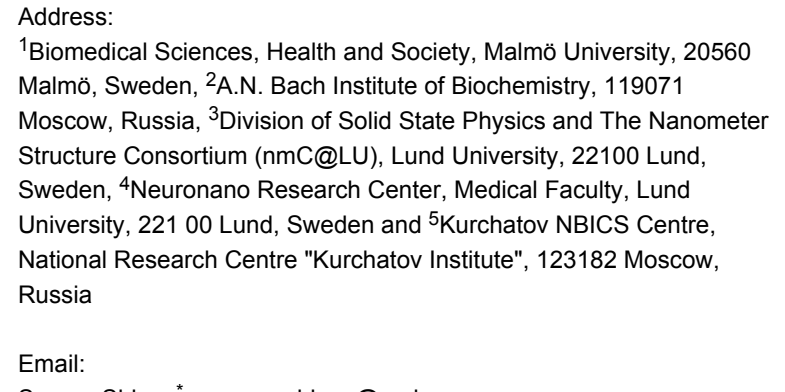

${ }^{1}$ Biomedical Sciences, Health and Society, Malmö University, 20560 Malmö, Sweden, ${ }^{2}$ A.N. Bach Institute of Biochemistry, 119071 Moscow, Russia, ${ }^{3}$ Division of Solid State Physics and The Nanometer Structure Consortium (nmC@LU), Lund University, 22100 Lund, Sweden, ${ }^{4}$ Neuronano Research Center, Medical Faculty, Lund University, 22100 Lund, Sweden and ${ }^{5}$ Kurchatov NBICS Centre, National Research Centre "Kurchatov Institute", 123182 Moscow, Russia

\section{Email:}

Sergey Shleev* - sergey.shleev@mah.se

* Corresponding author

\section{Keywords:}

bilirubin oxidase; bio-electrocatalysis; direct electron transfer; nanoimprint lithography; oxygen reduction reaction
Beilstein J. Nanotechnol. 2015, 6, 1377-1384. doi:10.3762/bjnano.6.142

Received: 02 March 2015

Accepted: 20 May 2015

Published: 22 June 2015

Associate Editor: R. Xu

(C) 2015 Pankratov et al; licensee Beilstein-Institut. License and terms: see end of document.

\begin{abstract}
Here we detail high performance, enzymatic electrodes for oxygen bio-electroreduction, which can be easily and reproducibly fabricated with industry-scale throughput. Planar and nanostructured electrodes were built on biocompatible, flexible polymer sheets, while nanoimprint lithography was used for electrode nanostructuring. To the best of our knowledge, this is one of the first reports concerning the usage of nanoimprint lithography for amperometric bioelectronic devices. The enzyme (Myrothecium verrucaria bilirubin oxidase) was immobilised on planar (control) and artificially nanostructured, gold electrodes by direct physical adsorption. The detailed electrochemical investigation of bioelectrodes was performed and the following parameters were obtained: open circuit voltage of approximately $0.75 \mathrm{~V}$, and maximum bio-electrocatalytic current densities of $18 \mu \mathrm{A} / \mathrm{cm}^{2}$ and $58 \mu \mathrm{A} / \mathrm{cm}^{2}$ in airsaturated buffers versus $48 \mu \mathrm{A} / \mathrm{cm}^{2}$ and $186 \mu \mathrm{A} / \mathrm{cm}^{2}$ in oxygen-saturated buffers for planar and nanostructured electrodes, respectively. The half-deactivation times of planar and nanostructured biocathodes were measured to be $2 \mathrm{~h}$ and $14 \mathrm{~h}$, respectively. The comparison of standard heterogeneous and bio-electrocatalytic rate constants showed that the improved bio-electrocatalytic performance of the nanostructured biocathodes compared to planar biodevices is due to the increased surface area of the nanostructured electrodes, whereas their improved operational stability is attributed to stabilisation of the enzyme inside nanocavities.
\end{abstract}




\section{Introduction}

Reduction of oxygen $\left(\mathrm{O}_{2}\right)$ is the key reaction in many natural and artificial systems, and indeed, this reaction is one of the most interesting research issues in both academia and industry today due to its importance in fuel cell technology [1]. The development of new, low cost, high activity catalysts for $\mathrm{O}_{2}$ reduction is under intensive investigation, with a special focus on renewable biological catalysts, such as living cells, organelles, and different redox enzymes, especially multicopper oxidases (MCOs) [2,3]. In nature, MCOs catalyse the oxidation of many organic and inorganic compounds (electron donors) using $\mathrm{O}_{2}$ as the only electron acceptor [4]. The $\mathrm{O}_{2}$ bioelectroreduction mechanism involves electron transfer from the electrode to the $\mathrm{T} 1$ copper $(\mathrm{Cu})$ site with the concomitant reduction of $\mathrm{O}_{2}$ directly to $\mathrm{H}_{2} \mathrm{O}$ in a trinuclear $\mathrm{Cu}$ cluster (T2/T3 Cu cluster) positioned 12-13 $\AA$ away [5-7], without releasing reactive $\mathrm{O}_{2}$ species, such as hydrogen peroxide or superoxide radicals $[8,9]$. Three-dimensional electrodes for enzyme-based cathodes are usually used to design high performance biodevices based on MCOs and different nanomaterials [10-14]. Several techniques for reproducible fabrication of well-ordered porous electrodes have been already reported. The techniques are based on electrodeposition of metals using colloidal templates [15] or gas bubbling [16]. Nevertheless, the simple and irreproducible immobilisation of separately synthesised nanomaterials on electrode surfaces is typically achieved. This approach cannot be directly used on an industrial scale and renders one of the main general problems of bioelectronics, which hinders real, practical application of biodevices including biocathodes.

Here we show fabrication of nanostructured electrodes using nanoimprint lithography (NIL), which ensures the wellcontrolled nanostructured geometry of electrodes on an industrial scale. To the best of our knowledge, this is one of the first reports concerning the application of NIL for amperometric bioelectronics. NIL is a parallel patterning technique capable of rendering features as small as $2-3 \mathrm{~nm}$ (or even smaller) in a fast, reproducible, scalable and economical way [17]. Nanoimprinting is based on the pattern transfer by a replication technique where nanometer-sized features of a hard stamp (mould) are copied into a polymer layer by either a thermal or an UV-light imprint process. The very high resolution of nanoimprinting can be combined with printing on large areas (6 inches and larger) and industry-scale throughput. In our studies, we used a well-known and commercially available MCO, bilirubin oxidase (BOx), which is one of the main biocatalysts exploited today to design third-generation (i.e., direct electron-transferbased), $\mathrm{O}_{2}$ reducing biodevices (e.g., $\mathrm{O}_{2}$-sensitive biosensors [18] and biocathodes of enzymatic fuel cells [19]). Contrary to many other MCOs, BOx is bio-electrocatalytically active when physically adsorbed on bare gold (Au), and the adsorption process is more or less irreversible [20]. Moreover, BOx-based biocathodes are highly active and stable across broad $\mathrm{pH}(5-8)$ and temperature $\left(0-40{ }^{\circ} \mathrm{C}\right)$ ranges $[5,21]$ in the presence of usual inhibitors of MCOs (e.g., halide ions [22]). Thus, we show one possible way to easily and reproducibly design (with industry-scale throughput) highly active and stable nanostructured biocathodes, which in principle can operate in solutions of different composition, temperature, and $\mathrm{pH}$.

\section{Results and Discussion}

Firstly, planar (control) and nanostructured (using NIL) Au electrodes (Au and NIL/Au electrodes, respectively) were fabricated. As control studies, electrochemically cleaned Au electrodes were imaged using AFM and SEM (Figure 1). According to AFM, the Au electrodes had a granular surface, in good agreement with previous reports [20,23]. Specifically, the grains exhibited lateral dimensions in the range of $20-80 \mathrm{~nm}$, and vertical dimensions in the $1-8 \mathrm{~nm}$ range, resulting in a roughness factor $(f)$ of the Au surface equal to $1.06 \pm 0.02$ (Figure 1a, left). Indeed, for Au electrodes $A_{\text {real }}$ was only 1.12-fold higher compared to $A_{\text {geom }}$. It is clearly seen that the NIL modification resulted in the formation of a regular, well-ordered, 2D hexagonal lattice of nanocavities, increasing the $f$ value to $1.65 \pm 0.03$ (Figure 1a, right). The centres of the nanocavities were separated by an average distance of approximately $300 \mathrm{~nm}$, whereas their depth was $208 \pm 13 \mathrm{~nm}$ or $106 \pm 9 \mathrm{~nm}$, depending on the directions defined by the two different primitive translation vectors of the lattice, as was revealed by AFM (Figure 1a, Figure S2 in Supporting Information File 1). On the one hand, the SEM studies and electrochemical investigations of $\mathrm{Au}$ and NIL/Au electrodes resulted in similar data (i.e., NIL modification significantly increased the roughness of the Au surface). On the other hand, contrary to AFM, much higher $f$ values were obtained, viz. $1.7 \pm 0.1$ and $5.5 \pm 0.5$, for $\mathrm{Au}$ and NIL/Au electrodes, respectively, as calculated from electrochemical data. The underestimated $f$ values revealed in the AFM studies might be attributed to different factors. For instance, AFM is not sensitive to roughness smaller than that of the tip. Moreover, due to its finite size, it may be that the tip does not reach the bottom of the nanocavities. In this case the corresponding area will not be included in the estimation of the $f$ value. Therefore, in our calculations, $f$ values from the electrochemical studies were used.

Secondly, electrochemical investigations of $\mathrm{Au}$ and NIL/Au electrodes were also performed in the $\mathrm{O}_{2}$-containing buffer, PBS, over the potential range of 0.0-0.6 V vs SCE (0.24-0.84 V vs NHE). Electrocatalytic reduction of $\mathrm{O}_{2}$ was not observed, neither on the $\mathrm{Au}$ nor the NIL/Au electrodes (Figure 2, curves 1' and 2'). 

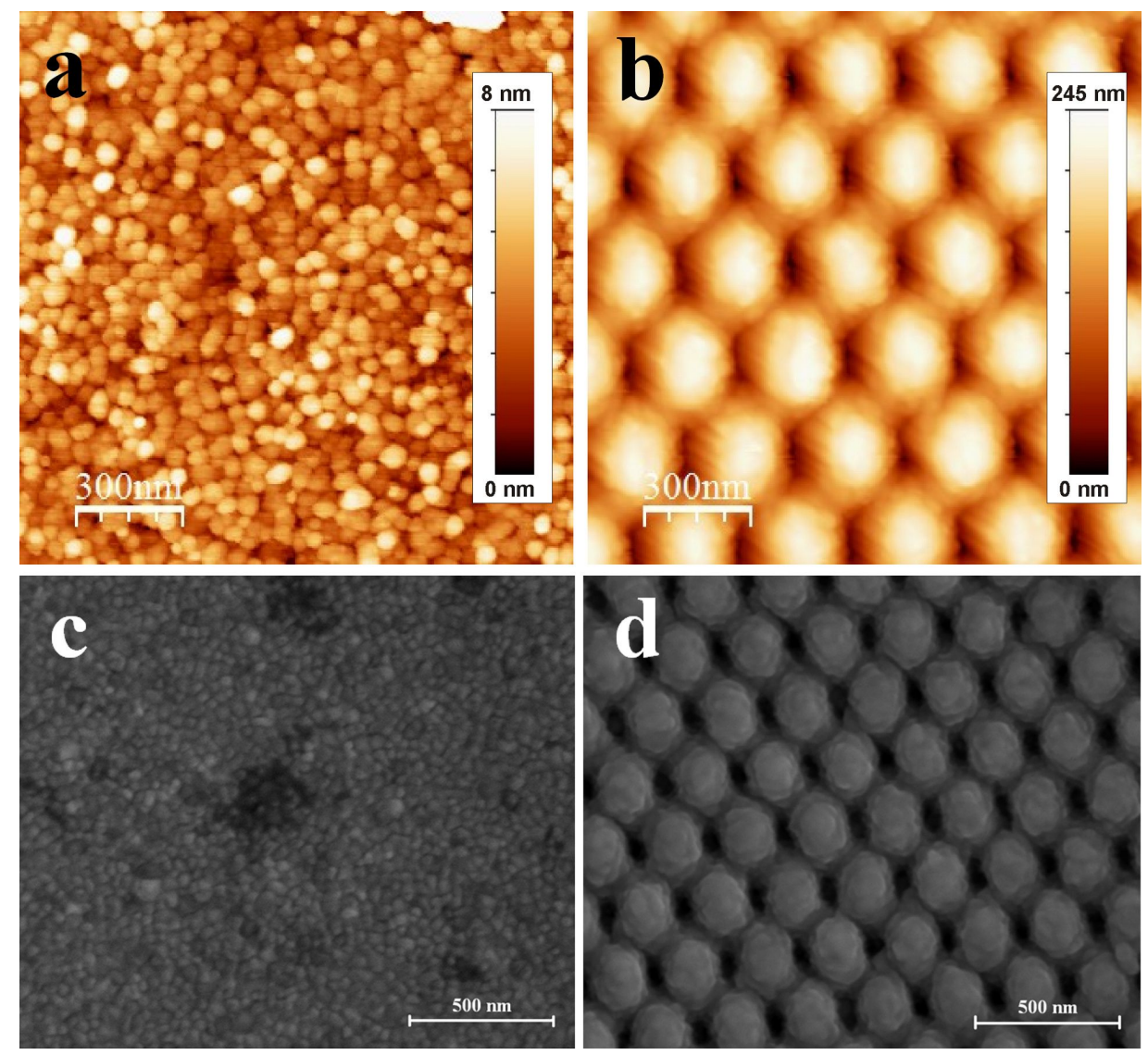

Figure 1: $\operatorname{AFM}(a, b)$ and SEM (c, d) images of a Au electrode $(a, c)$ and a NIL/Au electrode $(b, d)$.

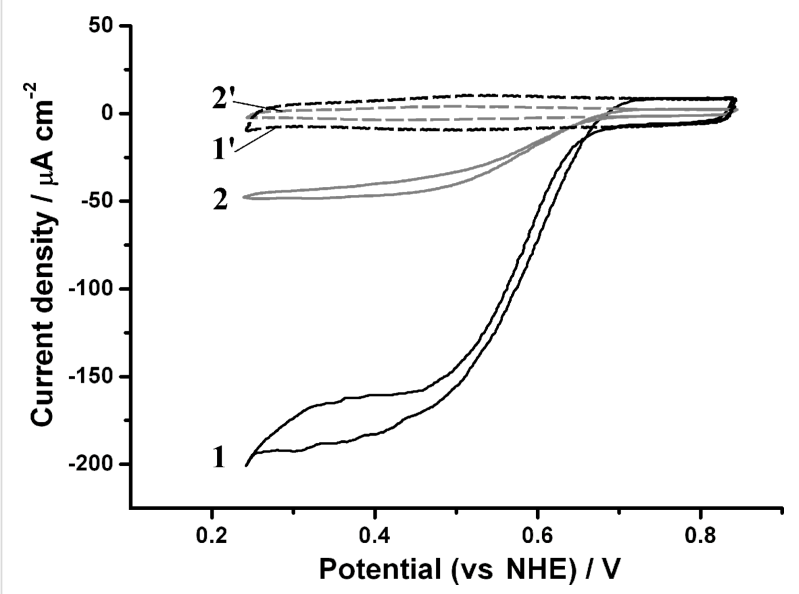

Figure 2: CVs of an NIL/Au electrode (1, 1') and a Au electrode (2, 2') modified with $\operatorname{MvBOx}(1,2)$ and without enzyme biomodification (1', 2'). Conditions: $\mathrm{O}_{2}$-saturated PBS, $\mathrm{pH} 7.4 ; 20 \mathrm{mV} \mathrm{s}^{-1}$ scan rate; second cycle.
Thus, the biological catalyst, BOx, was immobilised on the $\mathrm{Au}$ and NIL/Au electrodes. When the electrochemical measurements of the biomodified electrodes (both $\mathrm{BOx} / \mathrm{Au}$ and $\mathrm{BOx} /$ $\mathrm{NIL} / \mathrm{Au}$ ) were performed in $\mathrm{O}_{2}$-saturated $\mathrm{PBS}$, an open-circuit potential (OCP) of $\mathrm{O}_{2}$ bio-electroreduction for both types of electrodes was recorded as $0.75 \pm 0.03 \mathrm{~V}$ vs NHE, that is, very close to the redox equilibrium potential of the $\mathrm{O}_{2} / \mathrm{H}_{2} \mathrm{O}$ couple under these conditions $\left(0.79 \mathrm{~V}\right.$ vs NHE at $\left.\mathrm{pH} 7.4,25^{\circ} \mathrm{C}\right)$. This indicates the high bio-electrocatalytic activity of the biomodified electrodes towards $\mathrm{O}_{2}$. Indeed, well-pronounced bio-electrocatalytic currents were measured when the CVs were recorded in the potential range of $0.24-0.84 \mathrm{~V}$ vs NHE (Figure 2, curves 1 and 2). Maximum bio-electrocatalytic current densities $\left(j_{\max }\right)$ of $48 \mu \mathrm{A} \cdot \mathrm{cm}^{-2}$ and $186 \mu \mathrm{A} \cdot \mathrm{cm}^{-2}$ for $\mathrm{BOx} / \mathrm{Au}$ and $\mathrm{BOx} / \mathrm{NIL} / \mathrm{Au}$ electrodes, respectively, were obtained. When the $\mathrm{O}_{2}$ concentration was decreased from $1.2 \mathrm{mM}$ down to $0.25 \mathrm{mM}$ (by saturating the PBS with air instead of oxygen) the maximum current densities of bio-electrocatalytic $\mathrm{O}_{2}$ reduction also decreased by factors of 2.7 and 3.2 for the $\mathrm{BOx} / \mathrm{Au}$ and $\mathrm{BOx} / \mathrm{NIL} / \mathrm{Au}$ electrodes, respectively (Supporting Information File 1, Figures S3 and S4). This result 
implies the absence of a serious $\mathrm{O}_{2}$ diffusion limitation in our electrochemical systems, since in such a case the observed current decrease should be much greater (additional details can be found in Supporting Information File 1). The basic bio-electrocatalytic characteristics of $\mathrm{BOx} / \mathrm{Au}$ and $\mathrm{BOx} / \mathrm{NIL} / \mathrm{Au}$ electrodes are summarised in Supporting Information File 1, Table $\mathrm{S} 1$. Au and NIL/Au electrodes with different surface concentrations of the enzyme $(\Gamma)$ were investigated electrochemically. The maximum bio-electrocatalytic signal was obtained when using $40 \mu \mathrm{g} \cdot \mathrm{mL}^{-1}$ of BOx solution for bio-modification (Supporting Information File 1, Figures S6 and S7). Further increase in enzyme concentration suppressed the current, suggesting the formation of enzyme multilayers. These results are in good agreement with our recent report concerning the interfacial behaviour and activity of BOx immobilised on bare polycrystalline gold surfaces [20].

Thirdly, standard heterogeneous electron transfer rate constants $\left(k_{0}\right)$ and apparent bio-electrocatalytic constants $\left(k_{\mathrm{cat}}{ }^{\text {app }}\right.$, i.e., $k_{\mathrm{cat}}$ for BOx adsorbed on a Au surface), were calculated based on mathematical modelling (modelled vs experimental curves are presented in Supporting Information File 1 , Figure S8). $k_{0}$ values for both $\mathrm{BOx} / \mathrm{Au}$ and $\mathrm{BOx} / \mathrm{NIL} / \mathrm{Au}$ electrodes were found to be equal to $27 \mathrm{~s}^{-1}$. It appears that the heterogeneous electron transfer rate for the adsorbed BOx does not depend on electrode nanostructuring. These results are in excellent agreement with our previously published data concerning the influence of gold nanoparticles on enzymatic bio-electrocatalysis [24]. $k_{\text {cat }}{ }^{\text {app }}$ values for $\mathrm{BOx} / \mathrm{Au}$ and $\mathrm{BOx} / \mathrm{NIL} / \mathrm{Au}$ electrodes were found to be 30 and $39 \mathrm{~s}^{-1}$, respectively (Supporting Information File 1, Table S1), whereas $k_{\text {cat }}$ in homogeneous catalysis was measured to be $57 \mathrm{~s}^{-1}$ (see above). $k_{\text {cat }}{ }^{\text {app }}$ values for $\mathrm{BOx} / \mathrm{Au}$ and $\mathrm{BOx} / \mathrm{NIL} / \mathrm{Au}$ electrodes were recorded at 30 and $39 \mathrm{~s}^{-1}$, respectively (Supporting Information File 1, Table S1), whereas $k_{\text {cat }}$ in homogeneous solution was $57 \mathrm{~s}^{-1}$ (see above). Thus, the $k_{\text {cat }}$ and $k_{\text {cat }}$ app values do not differ much, suggesting retention of enzymatic activity after physisorption, which is in good agreement with our recently published results [20]. Moreover, it seems as though the biocatalytic activity of adsorbed BOx does not depend on electrode nanostructuring. The overpotential for both $\mathrm{BOx} / \mathrm{Au}$ and $\mathrm{BOx} / \mathrm{NIL} / \mathrm{Au}$ electrodes was found to be only approximately $0.04 \mathrm{~V}$ (see above) and could not be increased further due to thermodynamical constrains. Thus, one cannot explain the significant increase in bio-electrocatalytic signals after NIL just by using $k_{0}$ and/or $k_{\text {cat }}$ app values calculated for two different surfaces. However, when the $A_{\text {real }} / A_{\text {geom }}$ values of $\mathrm{Au}$ and NIL/Au electrodes (1.7 vs 5.5, respectively) are compared with the $j_{\max }$ values measured for $\mathrm{BOx} / \mathrm{Au}$ and $\mathrm{BOx} / \mathrm{NIL} / \mathrm{Au}$ electrodes $\left(18 \mu \mathrm{A} \cdot \mathrm{cm}^{-2}\right.$ vs $58 \mu \mathrm{A} \cdot \mathrm{cm}^{-2}$ in airsaturated and $48 \mu \mathrm{A} \cdot \mathrm{cm}^{-2}$ vs $186 \mu \mathrm{A} \cdot \mathrm{cm}^{-2}$ in oxygen-saturated PBS), an obvious correlation can be seen. Thus, the experi- mental results confirm that the improved bio-electrocatalytic currents of BOx/NIL/Au compared to BOx/Au can be simply attributed to an increase in the $A_{\text {real }}$ of the electrodes.

Finally, the operational stability of the bio-modified electrodes was also investigated. The half-deactivation times of $\mathrm{BOx} / \mathrm{Au}$ and BOx/NIL/Au biocathodes were found to be approximately 2 and 14 h, respectively. Thus, the current output of both Auand NIL/Au-based biocathodes clearly decreased with time (Figure 3).

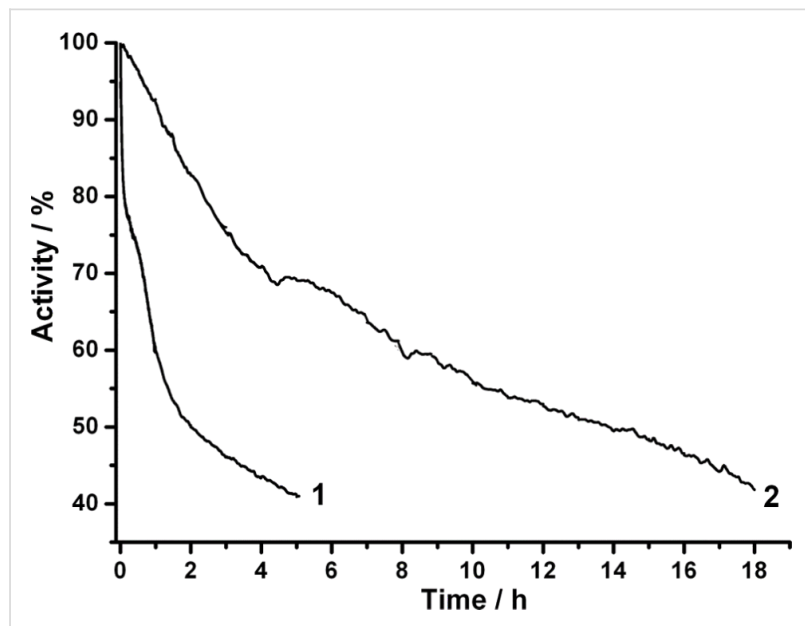

Figure 3: Chronoamperometric responses from a BOx/Au electrode (1) and a BOx/NIL/Au electrode (2). Conditions: $\mathrm{O}_{2}$-saturated PBS, $\mathrm{pH} 7.4 ;+400 \mathrm{mV}$ potential applied.

Since BOx was immobilised on the electrode simply by physical adsorption, this could be attributed to enzyme desorption from the Au surfaces. For this reason, additional qualitative (monitoring of enzyme activity in electrolytes) and quantitative (monitoring of the enzyme layer on Au surface using ellipsometry) studies were performed. In both measurements no indication of BOx desorption from the Au surface was observed. Specifically, no colour difference between the electrolyte (20 mL of PBS, pH 7.4) used in the electrochemical measurements with added enzyme substrates $(5 \mathrm{mM}$ ABTS and $0.25 \mathrm{mM} \mathrm{O}_{2}$ ) was observed compared to the control solution (air-saturated PBS containing $5 \mathrm{mM} \mathrm{ABTS}$, which was not in a contact with BOx modified electrodes). However, a wellpronounced colour change developed in electrolytes that were in contact with BOx-modified electrodes during the assays. Moreover, the ellipsometry data clearly showed that after rinsing no desorption of the enzyme took place: the adsorbed amount being approximately constant with a value of approximately $2.6 \mathrm{pmol} \cdot \mathrm{cm}_{\text {real }}{ }^{-2}$ (Supporting Information File 1, Figure $\mathrm{S} 8 \mathrm{a})$. This is close to a dense monolayer of BOx on the $\mathrm{Au}$ surface, taking into account that the footprint of the enzyme is about $3 \times 10^{-13} \mathrm{~cm}^{2}$. Furthermore, it was observed that the 
thickness of the adsorbed BOx layer gradually decreased, whereas its refractive index (i.e., its density) gradually increased (Supporting Information File 1, Figure S8b,c). This indicates a gradual flattening and compression of the enzyme layer on Au electrodes, which can be considered the origin of the eventual deactivation of the physically adsorbed BOx on bare Au surfaces, as already pointed out in our previous studies [20]. However, based on previous theoretical studies [25], since the $k_{\mathrm{cat}}{ }^{\text {app }}$ value for $\mathrm{BOx} / \mathrm{NIL} / \mathrm{Au}$ electrodes is higher compared to $\mathrm{BOx} / \mathrm{Au}$ (39 and $30 \mathrm{~s}^{-1}$, respectively) and no enzyme desorption was observed in our investigations, the significantly improved operational stability of the nanostructured biocathodes compared to "planar" biodevices might be attributed to stabilisation of the enzyme inside nanocavities that are formed by surface nanostructuring using NIL (cf. Figure 1 left (a and c) and right (b and d) images).

\section{Conclusion}

To the best of our knowledge, here we detail one of the first studies in the field of enzyme-based bioelectronics describing high-performance, nanostructured bioelectrodes that can be easily and reproducibly fabricated with industry-scale throughput. Biocompatible, polymer-based, flexible electrodes were fabricated with nanoimprinting, metallisation and biomodification. The very pronounced bio-electrocatalytic reduction of $\mathrm{O}_{2}$ in chloride-containing neutral buffers was obtained when the electrodes were biomodified with BOx by simple physical adsorption, which has an irreversible character. Detailed studies of the biocathodes showed that the nanostructured polymer surface provides an approximately 4 -fold increase in bio-electrocatalytic current density and an approximately 7-fold increase in the operational stability of the biocathodes compared to planar bioelectrodes. Whereas the bio-electrocatalytic signals are based on an increase in surface area, the improved stability might be attributed to the specific nanogeometry of the fabricated electrodes.

\section{Experimental \\ Chemicals}

Unless otherwise specified, all chemicals were purchased from Sigma-Aldrich GmbH (Schnelldorf, Germany). Acetone was purchased from Merck KGaA (Darmstadt, Germany). All solutions were prepared using water purified with the PURELAB UHQ II system from ELGA Labwater (High Wycombe, UK). Nitrogen $\left(\mathrm{N}_{2}\right)$ was additionally purified using gas clean filters from Varian BV (Middelburg, The Netherlands), and $\mathrm{O}_{2}$ was obtained from AGA Gas AB (Sundbyberg, Sweden).

\section{Redox enzyme}

Myrothecium verrucaria BOx was obtained as a kind gift from Amano Enzyme, Inc. (Nagoya, Japan). The specific activity of
BOx, measured to be $140 \mathrm{U} \cdot \mathrm{mg}^{-1}$, was determined using $5 \mathrm{mM}$ 2,2'-azino-bis(3-ethylbenzthiazoline-6-sulfonic acid) (ABTS) as an electron donor dissolved in phosphate buffered saline (PBS; $50 \mathrm{mM}$ phosphate buffer containing $0.15 \mathrm{M} \mathrm{NaCl}$ ), $\mathrm{pH} 7.4$, by measuring $\mathrm{O}_{2}$ consumption with a Oxygraph Clark-type electrode from Hansatech, Ltd. (Norfolk, England). Taking into account the molecular weight of the enzyme (close to $59 \mathrm{kDa}$ [20]), the measured specific activity of $140 \mathrm{U} \cdot \mathrm{mg}^{-1}$ corresponds to the observed biocatalytic constant $\left(k_{\mathrm{cat}}\right)$ of Myrothecium verrucaria $\mathrm{BOx}$ of about $58 \mathrm{~s}^{-1}$. Since ABTS has a very high molar extinction coefficient $\left(\varepsilon_{418}=36000 \mathrm{M}^{-1} \cdot \mathrm{cm}^{-1}\right)$ the compound was also used for qualitative determination of possible BOx activity in electrolytes [26] due to enzyme desorption from $\mathrm{Au}$ surfaces.

\section{Electrode fabrication and characterisation Fabrication of imprinted substrates}

The nanostructured electrodes were fabricated by a thermal NIL process using a nickel stamp purchased from NIL Technologies ApS (Kongens Lyngby, Denmark). The NIL stamp, produced by nickel electroplating, had an array of $100 \mathrm{~nm}$ features defined by UV-interference lithography. The stamp had undergone an anti-sticking treatment, resulting in a thin monolayer, self-assembling film of fluorinated alkyl phosphoric acid derivatives, as described in [27]. The pattern transfer step included imprinting using a 6" imprinter machine from Obducat Technologies AB (Lund, Sweden) onto a polymer sheet at $160{ }^{\circ} \mathrm{C}$ using an imprint pressure of 50 bar for $120 \mathrm{~s}$ and demoulding of the stamp at $115^{\circ} \mathrm{C}$ for $40 \mathrm{~s}$. For the imprint material, $20 \times 20 \mathrm{~cm}$ sheets of the intermediate polymer stamp (IPS ${ }^{\circledR}$ ) foil, provided by Obducat Technologies AB, was used. The IPS ${ }^{\circledR}$ material is a thermoplastic polymer suitable for thermal imprint with nickel stamps, but its exact composition has not been revealed by the manufacturer. In the current work, the polymer sheet was used to make the nanostructured electrodes with the active Au surface, thus the composition of the nanostructured polymer film had no significance in the current study. Imprinted and non-imprinted sheets of plastic were cut into $10 \times 10 \mathrm{~mm}^{2}$ pieces with scissors, henceforth called nanostructured and planar sheets, respectively. These were cleaned in acetone at room temperature for 2 min, and dried with $\mathrm{N}_{2}$ gas.

\section{Thermal evaporation of metal films}

All samples were covered with $5 \mathrm{~nm}$ of Ti followed by $100 \mathrm{~nm}$ of Au by thermal evaporation in a custom built system at low pressure. Titanium wire $(99.99+\%)$ was used as the Ti source and was purchased from Goodfellow Cambridge, Ltd. (Huntingdon, England), while the Au nuggets (99.9999\%) used as the $\mathrm{Au}$ source were purchased from Dahlgren Ädelmetall AB (Malmö, Sweden). The metal films were evaporated at a base pressure of $<10^{-6}$ mbar with an average deposition rate of 
$1 \AA \cdot \mathrm{s}^{-1}$ and $10 \AA \cdot \mathrm{s}^{-1}$ for Ti and Au, respectively. The $5 \mathrm{~nm}$ thick layer of Ti was deposited to promote the adhesion of the $\mathrm{Au}$ layer on the substrates. Supporting Information File 1, Figure $\mathrm{S} 1$ shows the fabrication process flow of the nanostructured electrodes.

\section{Characterisation of gold electrodes}

Surface morphology was studied using scanning electron microscopy (SEM) and atomic force microscopy (AFM). SEM images were taken using a Nova NanoLab 600 Dual Beam focused ion beam and scanning electron microscope (FIB-SEM) from FEI Company (Hillsboro, Oregon, USA). The images were taken with an immersion lens at an acceleration voltage of $30 \mathrm{kV}$ and a beam current of $2.4 \mathrm{nA}$. AFM images were obtained using a Multimode VIII SPM with a Nanoscope V control unit from Bruker AXS (Santa Barbara, CA, USA). The AFM was operated in the ScanAsyst mode. All images were obtained in air and at room temperature. Triangular silicon nitride cantilevers with a nominal spring constant of $0.4 \mathrm{~N} \cdot \mathrm{m}^{-1}$ (ScanAsyst Air probes, Bruker AXS) were employed in all measurements. The analysis and processing of the AFM images was performed with the WSxM software package [28]. Image processing consisted of plane subtraction, equalisation, and 3D representation.

The electrochemical measurements of the Au electrodes were performed in $0.5 \mathrm{M} \mathrm{H}_{2} \mathrm{SO}_{4}$ to clean the $\mathrm{Au}$ electrodes and to assure uniform $\mathrm{Au}$ surfaces on an atomic level, as well as to determine the real (also called microscopic or electrochemically active) electrode areas $\left(A_{\text {real }}\right)$ [29]. For this purpose, fabricated $\mathrm{Au}$ electrodes were connected as working electrodes to a $\mu$ Autolab Type III/FRA2 potentiostat/galvanostat from MetrohmAutolab B.V. (Utrecht, The Netherlands) using Au-plated alligator clips (model 3289-2, Pomona Electronics, Everett, WA, USA). These were placed into a standard electrochemical cell with a final electrolyte volume of $20 \mathrm{~mL}$ and subjected to an oxidation-reduction cycle in $0.5 \mathrm{M} \mathrm{H}_{2} \mathrm{SO}_{4}$ between 0 and $+1.9 \mathrm{~V}$ vs NHE at a scan rate of $0.1 \mathrm{~V} \cdot \mathrm{s}^{-1}$ for 10 cycles. In a three-electrode configuration, a $\mathrm{Hg} / \mathrm{Hg}_{2} \mathrm{Cl}_{2} /$ $\mathrm{KCl}_{\text {sat }}$ electrode (SCE, $242 \mathrm{mV}$ vs NHE) and a platinum wire mesh were applied as reference and counter electrodes, respectively. $A_{\text {real }}$ of the Au electrodes was calculated from the experimentally measured charge $\left(q_{\text {real }}\right)$ associated with the Au oxide reduction process performed by running cyclic voltammetry (Supporting Information File 1, Figure S1). A current peak related to the reduction of the $\mathrm{Au}$ was integrated to calculate $q_{\text {real }}$. The theoretical charge density $\left(\sigma_{t}\right)$ associated with this process was taken to be $390 \mu \mathrm{C} \cdot \mathrm{cm}^{-2}$ [29].

$$
A_{\text {real }}=q_{\text {real }} / \sigma_{\mathrm{t}}
$$

The microscopic roughness factor $(f)$ was calculated from Equation 2:

$$
A_{\text {real }}=A_{\text {geom }} \times f
$$

The geometric area $\left(A_{\text {geom }}\right.$, also called the two-dimensional projected area) of the electrodes was determined by direct precise geometric measurements using a Vernier caliper from Mitutoyo Scandinavia AB (Upplands Väsby, Sweden).

\section{Biomodification and investigation of bioelec- trodes Modification of gold surface with redox enzyme}

Clean Au electrodes with known $f$ values derived from electrochemical investigations (see above) were biomodified by simple adsorption of BOx on the electrode surface for 20 min using different solutions of the enzyme: from diluted to very concentrated (from $0.4 \mu \mathrm{g} \cdot \mathrm{mL}^{-1}$ up to $400 \mu \mathrm{g} \cdot \mathrm{mL}^{-1}$ in $10 \mathrm{mM}$ phosphate buffer, $\mathrm{pH} 7.4)$ at room temperature $\left(25^{\circ} \mathrm{C}\right)$. It should be emphasised that the electrodes were not allowed to dry out at any time during the modification and electrochemical investigations to avoid possible deactivation due to enzyme dehydration.

\section{Studies of biomodified electrodes}

The electrochemical measurements were performed in PBS saturated with air and $\mathrm{O}_{2}$. Cyclic voltammograms (CVs) and chronoamperograms were recorded using the equipment as described above.

After the electrochemical studies, additional tests concerning residual BOx activity in the electrolytes due to possible enzyme desorption from the electrode surface were performed. For this purpose $20 \mathrm{~mL}$ of an electrolyte, which was in contact with BOx-modified electrodes (i.e., after electrochemical measurements), was taken out and replaced with fresh PBS containing $5 \mathrm{mM}$ ABTS (control studies). Simultaneously, $5 \mathrm{mg}$ of ABTS was added to the electrolyte ( $20 \mathrm{~mL}$ of PBS, $\mathrm{pH} 7.4)$ used in the electrochemical measurements and possible colour change of the solution was monitored for $1 \mathrm{~h}$. As additional control measurements, air-saturated PBS containing $5 \mathrm{mM}$ ABTS (which was not in a contact with the BOx-modified electrodes) was always prepared and also monitored to estimate the autooxidation rate of ABTS by $\mathrm{O}_{2}$ under these conditions.

\section{Ellipsometry measurements}

The adsorption of BOx ( $40 \mu \mathrm{g} \cdot \mathrm{mL}^{-1}$ solution was used for biomodification) onto planar $\mathrm{Au}$ electrodes (with a roughness factor of about 1.7) was studied in situ by means of null ellipsometry in a similar manner as described in [20]. A thin film, automated ellipsometer (type 43 603-200E, Rudolph Research, 
Fairfield, NJ, USA) equipped with a xenon arc lamp with a fixed angle of incidence $\left(67.75^{\circ}\right)$ was exploited. In our calculations a refractive index increment of $0.18 \mathrm{~mL} \cdot \mathrm{g}^{-1}$ with respect to the change in protein concentration $(\mathrm{d} n / \mathrm{d} c)$ was used [30].

\section{Supporting Information}

\section{Supporting Information File 1}

FileFormat: PDF.

Supplementary data.

The Supporting Information provides additional electrochemical, AFM, and ellipsometry studies of the bioelectrodes, as well as the theoretical basis for the bio-electrochemical investigations and modelling. [http://www.beilstein-journals.org/bjnano/content/ supplementary/2190-4286-6-142-S1.pdf]

\section{Acknowledgements}

The authors thank Amano Enzyme, Inc. for the Amano 3 preparation of Myrothecium verrucaria bilirubin oxidase. Technical help from A. Kvennefors and M. Graczyk is highly appreciated. This work has been financially supported by the Swedish Research Council (2013-6006), Linnaeus grant (80658701), the Nanometer Structure Consortium at Lund University (nmC@LU) and by the Russian Foundation for Basic Research (13-04-12063 and 14-04-32235).

\section{References}

1. Jeon, M. K.; Lee, C. H.; Park, G. I.; Kang, K. H. J. Power Sources 2012, 216, 400-408. doi:10.1016/j.jpowsour.2012.05.107

2. Lau, C.; Adkins, E. R.; Ramasamy, R. P.; Luckarift, H. R.; Johnson, G. R.; Atanassov, P. Adv. Energy Mater. 2012, 2, 162-168. doi:10.1002/aenm.201100433

3. Pankratov, D. V.; Zeifman, Y. S.; Morozova, O. V.; Shumakovich, G. P.; Vasil'eva, I. S.; Shleev, S.; Popov, V. O.; Yaropolov, A. I. Electroanalysis 2013, 25, 1143-1149. doi:10.1002/elan.201200516

4. Solomon, E. I.; Sundaram, U. M.; Machonkin, T. E. Chem. Rev. 1996, 96, 2563-2605. doi:10.1021/cr950046o

5. dos Santos, L.; Climent, V.; Blanford, C. F.; Armstrong, F. A. Phys. Chem. Chem. Phys. 2010, 12, 13962-13974. doi:10.1039/c0cp00018c

6. Sakurai, T.; Kataoka, K. Cell. Mol. Life Sci. 2007, 64, 2642-2656. doi:10.1007/s00018-007-7183-y

7. Shleev, S.; Tkac, J.; Christenson, A.; Ruzgas, T.; Yaropolov, A. I.; Whittaker, J. W.; Gorton, L. Biosens. Bioelectron. 2005, 20, 2517-2554. doi:10.1016/j.bios.2004.10.003

8. Tarasevich, M. R.; Yaropolov, A. I.; Bogdanovskaya, V. A.; Varfolomeev, S. D. Bioelectrochem. Bioenerg. 1979, 6, 393-403. doi:10.1016/0302-4598(79)80006-9

9. Parimi, N. S.; Umasankar, Y.; Atanassov, P.; Ramasamy, R. P. ACS Catal. 2012, 2, 38-44. doi:10.1021/cs200527c
10. Dagys, M.; Haberska, K.; Shleev, S.; Arnebrant, T.; Kulys, J.; Ruzgas, T. Electrochem. Commun. 2010, 12, 933-935. doi:10.1016/j.elecom.2010.04.024

11. Jensen, U. B.; Vagin, M.; Koroleva, O.; Sutherland, D. S.; Besenbacher, F.; Ferapontova, E. E. J. Electroanal. Chem. 2012, 667, 11-18. doi:10.1016/j.jelechem.2011.12.012

12. Weigel, M. C.; Tritscher, E.; Lisdat, F. Electrochem. Commun. 2007, 9 , 689-693. doi:10.1016/j.elecom.2006.10.052

13. Zheng, W.; Li, Q.; Su, L.; Yan, Y.; Zhang, J.; Mao, L. Electroanalysis 2006, 18, 587-594. doi:10.1002/elan.200503444

14. Murata, K.; Kajiya, K.; Nakamura, N.; Ohno, H. Energy Environ. Sci. 2009, 2, 1280-1285. doi:10.1039/b912915d

15. Walcarius, A.; Kuhn, A. TrAC, Trends Anal. Chem. 2008, 27, 593-603. doi:10.1016/j.trac.2008.03.011

16. Huan, T. N.; Ganesh, T.; Kim, K. S.; Kim, S.; Han, S. H.; Chung, H. Biosens. Bioelectron. 2011, 27, 183-186. doi:10.1016/j.bios.2011.06.011

17. Schift, H. J. Vac. Sci. Technol., B 2008, 26, 458-480. doi:10.1116/1.2890972

18. Pita, M.; Gutierrez-Sanchez, C.; Toscano, M. D.; Shleev, S.; De Lacey, A. L. Bioelectrochemistry 2013, 94, 69-74. doi:10.1016/j.bioelechem.2013.07.001

19. Falk, M.; Blum, Z.; Shleev, S. Electrochim. Acta 2012, 82, 191-202. doi:10.1016/j.electacta.2011.12.133

20. Pankratov, D.; Sotres, J.; Barrantes, A.; Arnebrant, T.; Shleev, S. Langmuir 2014, 30, 2943-2951. doi:10.1021/la402432q

21. Shleev, S.; Andoralov, V.; Falk, M.; Reimann, C. T.; Ruzgas, T.; Srnec, M.; Ryde, U.; Rulíšek, L. Electroanalysis 2012, 24, 1524-1540. doi:10.1002/elan.201200188

22. Kim, H.-H.; Zhang, Y.; Heller, A. Anal. Chem. 2004, 76, 2411-2414. doi:10.1021/ac035487j

23. Caruso, F.; Furlong, D. N.; Kingshott, P. J. Colloid Interface Sci. 1997, 186, 129-140. doi:10.1006/jcis.1996.4625

24. Pankratov, D.; Sundberg, R.; Suyatin, D. B.; Sotres, J.; Barrantes, A.; Ruzgas, T.; Maximov, I.; Montelius, L.; Shleev, S. RSC Adv. 2014, 4, 38164-38168. doi:10.1039/C4RA08107B

25. Zhou, H.-X.; Dill, K. A. Biochemistry 2001, 40, 11289-11293. doi:10.1021/bi0155504

26. Zumárraga, M.; Bulter, T.; Shleev, S.; Polaina, J.; Martínez-Arias, A.; Plou, F. J.; Ballesteros, A.; Alcalde, M. Chem. Biol. 2007, 14, 1052-1064. doi:10.1016/j.chembiol.2007.08.010

27. Keil, M.; Beck, M.; Frennesson, G.; Theander, E.; Bolmsjö, E.; Montelius, L.; Heidari, B. J. Vac. Sci. Technol., B 2004, 22, 3283-3287. doi:10.1116/1.1824051

28. Horcas, I.; Fernandez, R.; Gomez-Rodríguez, J. M.; Colchero, J.; Gómez-Herrero, J.; Baro, A. M. Rev. Sci. Instrum. 2007, 78, 013705. doi:10.1063/1.2432410

29. Trasatti, S.; Petrii, O. A. Pure Appl. Chem. 1991, 63, 711-734. doi:10.1351/pac199163050711

30. De Feijter, J. A.; Benjamins, J.; Veer, F. A. Biopolymers 1978, 17, 1759-1772. doi:10.1002/bip.1978.360170711 


\section{License and Terms}

This is an Open Access article under the terms of the Creative Commons Attribution License

(http://creativecommons.org/licenses/by/2.0), which permits unrestricted use, distribution, and reproduction in any medium, provided the original work is properly cited.

The license is subject to the Beilstein Journal of Nanotechnology terms and conditions:

(http://www.beilstein-journals.org/bjnano)

The definitive version of this article is the electronic one which can be found at:

doi:10.3762/bjnano.6.142 